\title{
Cyclovirus Vietnam DNA in immunodeficient patients
}

\author{
Lisa Macera ${ }^{\mathrm{a}, \mathrm{b}, \mathrm{c}}$, Daniele Focosi ${ }^{\mathrm{d}}$, Maria Linda Vatteroni ${ }^{\mathrm{a}}$, Aldo Manzin $^{\mathrm{b}}$, \\ Guido Antonelli ${ }^{\mathrm{e}}$, Mauro Pistello ${ }^{\mathrm{a}, \mathrm{c}}$, Fabrizio Maggi ${ }^{\mathrm{a}, *}$ \\ a Virology Unit, Pisa University Hospital, Pisa, Italy \\ ${ }^{\mathrm{b}}$ Department of Biomedical Sciences, Microbiology and Virology Unit, University of Cagliari, Italy \\ ${ }^{\mathrm{c}}$ Retrovirus Center and Virology Section, Department of Translational Research, University of Pisa, Italy \\ ${ }^{\mathrm{d}}$ Division of Transfusion Medicine and Transplant Biology, Pisa University Hospital, Pisa, Italy \\ e Pasteur Institute-Cenci Bolognetti Foundation, Department of Molecular Medicine, Laboratory of Virology, Sapienza University of Rome, Italy
}

\section{A R T I C L E I N F O}

\section{Article history:}

Received 20 February 2016

Received in revised form 18 May 2016

Accepted 19 May 2016

\section{Keywords:}

Cyclovirus

CyCV-VN

HIV

Italy

Transplantation

\begin{abstract}
A B S T R A C T
Background: Cyclovirus Vietnam (CyCV-VN) is a CyCV detected in 2013 from cerebrospinal fluid (CSF) samples of patients with neurological disorders. Information on prevalence, pathogenesis and disease association of CyCV-VN is still very patchy.

Objectives and study design: In this study, we have used a PCR assay targeting the Rep gene to investigate the prevalence of CyCV-VN infection in blood and CSF samples of 346 Italian subjects.

Results: Overall, $7 \%$ of blood samples were positive for CyCV-VN while the virus was not detected in any of the CSF samples. The prevalence of CyCV-VN was relatively high in HIV positive patients (21\%), modest in patients with HBV or HCV infection (6\%), and low in transplant recipient patients (2\%). Positive patients showed low levels of CyCV-VN viremia. The virus was not detected in serum samples from healthy individuals. Longitudinal analysis of serum samples obtained from selected patients showed a stable or transient presence of circulating CyCV-VN.

Conclusions: The present study is the first to demonstrate CyCV-VN DNA circulation in Italy and to cast light on some biological aspects of this novel virus of men.
\end{abstract}

(C) 2016 Elsevier B.V. All rights reserved.

\section{Background and objectives}

Cycloviruses (CyCVs) are members of the recently proposed genus Cyclovirus within the family Circoviridae. They have small genomes which are circular, single-stranded DNA of about $2 \mathrm{~kb}$ containing two major inversely arranged open reading frames (ORFs). The two putative ORF proteins are believed to serve as capsid protein and viral replication associated protein (Rep). The genome also contains a potential stem-loop structure with a conserved nonanucleotide motif located between the ORF 5 -ends and probably important in initiating the replication of the viral genome [1]. CyCVs have been discovered in chimpanzees and wild animal fecal samples [2-5], rodent intestinal content [6,7], equine nasal secretions [8], insects [9-13], bats [14-18], farm animals such as cows, sheep, goats, and chickens [1,3,16], and felines [5] .

* Corresponding author at: Virology Unit, Pisa University Hospital, Via Paradisa 2, I-56127 Pisa, Italy.

E-mail addresses: fabrizio.maggi63@gmail.com, f.maggi@ao-pisa.toscana.it (F. Maggi)
In 2010 Li et al. first reported CyCV in 7-17\% stools from nonU.S. children with nonpolio acute flaccid paralysis, differentiating 25 potentially different species from several countries, such as Pakistan, Nigeria, and Tunisia (TN) [3]. CyCVs have been suggested to cause human enteric infections and human isolates showed limited genetic overlap with those derived from consumed food $[3,19]$. In 2013 CyCV-Vietnam (CyCV-VN) was detected in $4 \%$ of 642 cerebrospinal fluid (CSF) specimens of patients living in central and southern Vietnam and suffering central nervous system (CNS) infections [4]. A similar prevalence found in feces of healthy children suggested that CyCV-VN infection is transmitted via foodborne or orofecal transmission routes. The same study also found a high prevalence of infection in pigs and poultry (58\% feces scored positive for $\mathrm{CyCV}-\mathrm{VN}$ genome) suggesting the existence of animal reservoirs [4].

Another CyCV (CyCV-VS5700009) was recently identified in 15\% and $10 \%$ serum and CSF samples, respectively, of Malawian patients with unexplained paraplegia: interestingly, only 1 patient was positive in both CSF and serum [20]. To explore the geographic distribution of these novel viruses, Tan et al. [21] screened more than 600 CSF specimens from patients with suspected CNS infections in northern Vietnam, Cambodia, Nepal, and The Netherlands. 
Unexpectedly, none of them scored positive for CyCV-VN and CyCV-VS5700009 genome [21]. More recently, Garigliany et al. [2] reported the detection of CyCV-VN species in human stool samples from Madagascar and Ghana and pig stool samples from Cameroon, supporting the idea that CyCV-VN has a wide geographic distribution and animal reservoirs. In 2014, Phan et al. reported a third $\mathrm{CyCV}$ (CyCV-ChileNPA1) from 4 children with acute lower respiratory tract infections in Santiago, Chile, using a viral metagenomics approach [22]. Furthermore, a fourth potential CyCV (CyCV-VS6600022) was isolated in a Dutch patient with diarrhea [23]. Sequence comparison and phylogenetic analysis among these 4 isolates indicated that they represent distinct, but phylogenetically related, $\mathrm{CyCV}$ species.

In this study, serum and CSF samples from 346 patients were examined to establish the prevalence of CyCV infection in Italy. Analysis was carried out using a CyCV-VN Rep-targeted polymerase chain reaction (PCR) assay.

\section{Study design}

\subsection{Patients and samples}

A total of 346 randomly selected samples (294 sera and 52 CSF) from subjects living in central Italy were studied. All samples were collected between January and December 2013 and written informed consent was collected from each subject before being sampled. Most serum samples $(n=215)$ were from diseased patients whom blood samples had been submitted to our laboratory for routine virological analysis; the remaining 79 sera were from healthy blood donors. Diseased patients included 60 solid organ transplant recipients (32 kidney transplants, 28 liver transplant), and 155 chronically viremic patients ( 72 patients viremic for HIV RNA, 42 for HBV DNA, and 41 for HCV RNA) (Table 1). The 52 CSF samples were from patients with neurological disorders (i.e. meningitis, encephalitis). For a subset of CyCV positive patients, pre- and post-serum samples were available for confirmatory tests. Aliquots were immediately prepared, stored and kept under sterile conditions at $-80^{\circ} \mathrm{C}$ until use.

\section{CyCV DNA detection}

Viral nucleic acids were extracted from $200 \mu$ l serum or CSF using a commercial kit (QIAamp DNA blood kit, Qiagen, Hilden, Germany) and amplified with standard published PCR primers [4] and a newly designed real-time quantitative PCR using same following primers CyCV31-53F: 5'-GAGCGCACATTGAAAGAGCTAAA3', and CyCV178-153R: 5'- TCTCCTCCTTCAATGACAGAAACAAC-3'. Primers were designed on the Rep gene of the CyCV-VN genome [4], and have the potential for sensitive and specific PCR detection of viral isolates belonging to CyCV-VN species. For real-time quantitative PCR (qPCR), $20 \mu \mathrm{l}$ of reaction containing $10 \mu \mathrm{l}$ iTaq Universal SyBRGreen Supermix (BioRad, Hercules, CA, USA), $0.5 \mu \mathrm{M}$ forward and reverse primers and $3 \mu$ l DNA, were amplified with iQ5 Multicolor Real Time PCR System (Bio-Rad) and as follows: initial denaturation at $95^{\circ} \mathrm{C}$ for $5 \mathrm{~min}, 40$ cycles of $15 \mathrm{~s}$ at $95^{\circ} \mathrm{C}$, and $1 \mathrm{~min}$ at $60^{\circ} \mathrm{C}$. Specificity of amplified products was determined by melting curve analysis. Standard curves for template quantitation were produced with 10 -fold dilutions of CyCV-VN plasmid kindly provided by Dr. Le Van Tan (Centre for Tropical Medicine, Oxford University Clinical Research Unit, Ho Chi Minh City, Vietnam). This method detected about 30 copies per $\mathrm{ml}$ of serum. With standard PCR, amplification was carried out in $25 \mu \mathrm{l}$ reaction mixture containing 0.75 U DreamTaq Green DNA polymerase (ThermoScientific Waltham, MA, USA), $0.6 \mu$ M each primer, $0.2 \mathrm{mM}$ each deoxynucleoside triphosphate, $1 \mathrm{X}$ DreamTaq Green buffer, and $3 \mu \mathrm{l}$ of DNA template. PCR was performed in a T100 Thermal Cycler (Bio-Rad) with an initial denaturation step at $95^{\circ} \mathrm{C}$ for $3 \mathrm{~min}$, followed by 45 cycles at $95^{\circ} \mathrm{C}$ for $30 \mathrm{~s}, 55^{\circ} \mathrm{C}$ for $30 \mathrm{~s}, 72^{\circ} \mathrm{C}$ for $30 \mathrm{~s}$, and a final extension step of $72^{\circ} \mathrm{C}$ for $10 \mathrm{~min}$. PCR products were resolved on $2 \%$ agarose gels using a molecular size marker to estimate amplicon length (expected size $147 \mathrm{bp}$ ). To minimize contamination risk, serum handling, DNA extraction, PCR amplification, and electrophoresis analysis were carried out in separated rooms. Negative controls were added during DNA extraction and PCR amplification. To validate the amplification process, positive controls obtained from Le Van Tan were run in each PCR. All samples were tested with both PCRs and scored positive when CyCV-VN DNA was detected by both methods.

To further exclude PCR contamination and to demonstrate that CyCV-VN strains were present as complete genomes, a molecular approach combining the rolling circle amplification (RCA) technique $[24,25]$ with specific cyclovirus PCRs was performed. RCA was carried out in a $20 \mu \mathrm{l}$ format by using an optimized mix with $4 \mu \mathrm{l}$ of sample DNA, $25 \mu \mathrm{M}$ of exo resistant random primers, $4 \mathrm{mM}$ of dNTPs, and $10 \mathrm{U}$ of phi29 DNA polymerase. Amplification was performed at $30^{\circ} \mathrm{C}$ for $18 \mathrm{~h}$, followed by inactivation of phi29 DNA polymerase at $65^{\circ} \mathrm{C}$ for $10 \mathrm{~min}$. The resulting RCA DNA product was resolved on $0.6 \%$ agarose gel, spectrophotometrically quantified and then diluted to be used as the template in cyclovirus specific-PCRs.

\section{Results}

\subsection{Detection of $C y C V-V N D N A$}

As shown in Table 1, 21 of 294 serum samples were found positive for CyCV-VN DNA corresponding to a prevalence of infection of about $7 \%$ in the Italian population studied. Distribution was uneven: all sera from healthy controls were negative, 1 (out of 32 , $3 \%$ prevalence) was from a simultaneous kidney/pancreas transplant recipient (female, 50 years old), and 20 (out of $155,13 \%$ ) were from patients infected with HBV, HCV, or HIV. Two of these were HBV infected and had moderate levels of circulating HBV DNA(5277 and $272 \mathrm{UI} / \mathrm{ml}$, respectively); three were HCV infected (2 females, 1 male) with a mean HCV load of about $1.200 .000 \mathrm{UI} / \mathrm{ml}$ serum; and interestingly, 15 were HIV-positive patients (out of 72 tested HIV-positive patients, 21\%; 12 males, 3 females). The HIV-positive patients coinfected by CyCV-VN had a tendency to manifest lower mean HIV RNA levels (33.300 vs. 286.200 copies/ml) and mean CD4 counts (583 vs. 651/ $\mu$ l of blood) compared to CyCV-VN negative patients, but the differences were not statistically significant. No CSF from patients with neurological disorders tested positive (Table 1). To exclude PCR contamination, a number of virus-positive samples were re-tested by using RCA, which made it possible the preferential amplification of circular DNA genomes by random primers. All RCA products were confirmed CyCV-VN positive when amplified by the cyclovirus-specific protocols as in Materials and Methods (data not shown). Measuring of $\mathrm{CyCV}-\mathrm{VN}$ viremia in virus positive patients showed that was detected at serum loads of about $2.0 \log$ copies $/ \mathrm{ml}$ with no significant difference among the patients (Table 1).

\subsection{Longitudinal study of $C y C V-V N$ viremia}

Serial samples were available for five CyCV-VN DNA positive patients. As reported in Table 2, at least two samples scored positive for each HIV patient. Interestingly, patient CA, for whom we could examine six serum samples, harbored CyCV-VN DNA in his blood for at least 7 months. CyCV-VN DNA was instead intermittently found in the blood samples of other subjects. Patient AG, 
Table 1

Analysis of 346 selected human samples for CyCV-VN DNA detection.

\begin{tabular}{|c|c|c|c|c|c|}
\hline Sample & Source(s) & Female/Male & Mean age (yrs) & No. tested & CyCV-VN DNA positive (\%) \\
\hline \multicolumn{6}{|l|}{ Plasma } \\
\hline & Healthy subjects & $30 / 49$ & $41 \pm 10$ & 79 & $0(0)$ \\
\hline & Liver transplant recipients & $11 / 17$ & $57 \pm 16$ & 28 & $0(0)$ \\
\hline & Kidney/pancreas transplant recipients & $19 / 13$ & $51 \pm 12$ & 32 & $1(3)^{\mathrm{a}}$ \\
\hline & HBV positive patients & $12 / 30$ & $43 \pm 15$ & 42 & $2(5)$ \\
\hline & HCV positive patients & $14 / 27$ & $55 \pm 18$ & 41 & $3(7)$ \\
\hline & HIV positive patients & $20 / 52$ & $47 \pm 14$ & 72 & $15(21)$ \\
\hline \multicolumn{6}{|c|}{ Cerebrospinal fluid } \\
\hline & Neurological patients & $28 / 24$ & $49 \pm 10$ & 52 & $0(0)$ \\
\hline
\end{tabular}

a Mean CyCV-VN loads \pm standard deviation were: $192,100 \pm 10,179 \pm 50,180 \pm 20$ DNA copies for ml of serum for kidney/pancreas transplant recipient, HBV positive patients, HCV positive patients, and HIV positive patients, respectively.

Table 2

Time course of CyCV-VN DNA detection in serum samples from 5 patients.

\begin{tabular}{|c|c|c|c|c|c|c|c|c|}
\hline \multirow[t]{2}{*}{ Patient } & \multicolumn{8}{|c|}{ CyCV-VN DNA detection at selected time points (months) } \\
\hline & 0 & 1 & 2 & 3 & 4 & 5 & 6 & 7 \\
\hline \multicolumn{9}{|l|}{ HIV positive } \\
\hline Patient AG & $100 \mathrm{c} / \mathrm{ml}^{\mathrm{a}}$ & $N A^{b}$ & NA & NA & $150 \mathrm{c} / \mathrm{ml}$ & $<30 \mathrm{c} / \mathrm{ml}$ & NA & NA \\
\hline Patient CA & $80 \mathrm{c} / \mathrm{ml}^{\mathrm{a}}$ & NA & $120 \mathrm{c} / \mathrm{ml}$ & $570 \mathrm{c} / \mathrm{ml}$ & $180 \mathrm{c} / \mathrm{ml}$ & $100 \mathrm{c} / \mathrm{ml}$ & NA & $70 \mathrm{c} / \mathrm{ml}$ \\
\hline Patient NF & $165 \mathrm{c} / \mathrm{ml}^{\mathrm{a}}$ & $352 \mathrm{c} / \mathrm{ml}$ & NA & NA & NA & NA & NA & NA \\
\hline Patient PU & $<30 \mathrm{c} / \mathrm{ml}$ & NA & NA & NA & NA & NA & $85 \mathrm{c} / \mathrm{ml}^{\mathrm{a}}$ & $100 \mathrm{c} / \mathrm{ml}$ \\
\hline \multicolumn{9}{|l|}{ Transplant recipients } \\
\hline Patient MS & $<30 \mathrm{c} / \mathrm{ml}$ & $195 \mathrm{c} / \mathrm{ml}^{\mathrm{a}}$ & NA & $<30 \mathrm{c} / \mathrm{ml}$ & $<30 \mathrm{c} / \mathrm{ml}$ & $<30 \mathrm{c} / \mathrm{ml}$ & NA & NA \\
\hline
\end{tabular}

a Serum sample initially tested for CyCV-VN DNA; $\mathrm{c} / \mathrm{ml}$, copies per $\mathrm{ml}$ of serum.

b NA, Not available.

viremic at first sampling was also positive at month 4 but negative at month 5; patient PU was positive in the last samples and negative in the blood collected six months before. Finally, patient MS, who was positive in the sample collected at month 1 posttransplantation, was then consistently negative in the three samples collected at monthly interval post-transplantation. As shown in Table 2, all positive samples at selected time points showed low levels of CyCV-VN viremia.

\section{Discussion}

In order to elucidate the presence of $\mathrm{CyCV}-\mathrm{VN}$ in European countries other than The Netherlands, we screened a number of samples collected from diseased patients and healthy blood donors in central Italy. Serum samples were taken from 132 immunocompromised patients ( 72 patients with HIV infection and 60 transplant recipients), 83 co- infected patients (42 patients HBV-infected, and $41 \mathrm{HCV}$-infected), and 79 healthy blood donors. CSF samples were obtained from 52 patients with neurological disorders. CyCV-VN DNA was identified in the blood of $16(12 \%)$ individuals with dysfunction of their immune system, and $5(6 \%)$ co-infected subjects. No serum from immune-competent healthy donors and no CSF sample were found positive for $\mathrm{CyCV}$. Although we were unable to discriminate the exact $\mathrm{CyCV}-\mathrm{VN}$ species in our CyCV-DNA positive patients, our study reveals that $\mathrm{CyCV}$-VN-like sequences, which can be detected by our qPCR assay, are circulating in Italian population, thus extending previous findings about the geographic distribution of the virus.

These data raise a number of interesting points. Firstly in theory, the high rate of PCR detection, and the very low level of viral DNA could suggest possible PCR contamination. However, this possibility was completely excluded. All the laboratory procedures for minimizing the contamination risk were put underway, and importantly virus-positive samples were re-confirmed by using a preliminary step of RCA, supporting the claim that CyCV-VN strains were present as complete genomes. Also, potential PCR cross-reactivity with contaminating human genomic DNA [26] was excluded by sequencing all the 21 PCR fragments obtained. Twenty out of 21 isolates were clearly related to the previously published CyCV-VN sequence (99\% identical to isolate hcf5) while one serum sample from a HBV-positive patient yielded a sequence $99 \%$ identical to isolate TN18 (accession number: GQ404858). This strain is evolutionary different from CyCV-VN isolates and might represent a separate viral species.

Secondly, the presence of CyCV-VN DNA in the blood suggests that the infection is systemic, although the significance of viremia and underlying pathogenic process - if any - are unclear at the moment. Third, most patients in whom CyCV DNA was found had deficient immune system. This finding is not surprising since torquetenovirus, single- stranded DNA viruses genetically very similar to CyCV-VN, circulate in the blood of infected individuals at levels that show an intriguingly positive association with severity of immunedeficiency [27]. Fourth, the data collected over time, albeit small, suggests that viral DNA is a stable or transient presence in the blood of infected subjects. In particular, patient CA harbored CyCVVN DNA in his blood for at least 7 months. These findings could be the result of a short-lasting acute infection with subsequent reinfection or, alternatively, a persistent infection with viremia levels that fluctuates in close proximity of the sensitivity threshold of the PCR assays used. According to the latter hypothesis, the observation that the levels of CyCV-VN found during the follow-up of positive patients remained consistently low ranging around $10^{2}$ copies per $\mathrm{ml}$ of serum.

The present study is the first to investigate CyCV-VN DNA circulation in Italy and shed light on the biological aspects of this virus in humans. Further investigations are warranted to establish CyCV-VN epidemiology and understanding pathogenetic role and significant of this novel virus.

\section{Funding}

This study was supported by grants from Pasteur Institute, Cenci Bolognetti Foundation (call 2014). 


\section{Competing interests}

None.

\section{Ethical approval}

Written informed consent was obtained from each subject of the study.

\section{References}

[1] E. Delwart, L. Li, Rapidly expanding genetic diversity and host range of the Circoviridae viral family and other Rep encoding small circular ssDNA genomes, Virus Res. 164 (2012) 114-121.

[2] M.M. Garigliany, R.M. Hagen, H. Frickmann, J. May, N.G. Schwarz, A. Perse, et al., Cyclovirus CyCV-VN species distribution is not limited to Vietnam and extends to Africa, Sci. Rep. 4 (2014) 7552.

[3] L. Li, A. Kapoor, B. Slikas, O.S. Bamidele, C. Wang, S. Shaukat, et al., Multiple diverse circoviruses infect farm animals and are commonly found in human and chimpanzee feces, J. Virol. 84 (2010) 1674-1682

[4] Tan Le, H.R. van Doorn, H.D. Nghia, T.T. Chau, le T.P. Tu, M. de Vries, et al, Identification of a new cyclovirus in cerebrospinal fluid of patients with acute central nervous system infections, mBio 4 (2013) e00231-13.

[5] W. Zhang, L. Li, X. Deng, B. Kapusinszky, P.A. Pesavento, E. Delwart, Faecal virome of cats in an animal shelter, J. Gen. Virol. 95 (2014) 2553-2564.

[6] M. Sasaki, Y. Orba, K. Ueno, A. Ishii, L. Moonga, B. Hang'ombe, et al. Metagenomic analysis of the shrew enteric virome reveals novel viruses related to human stool-associated viruses, J. Gen. Virol. 96 (2015) 440-452.

[7] G. Sato, T. Kawashima, M. Kiuchi, Y. Tohya, Novel cyclovirus detected in the intestinal contents of Taiwan squirrels (Callosciurus erythraeus Thaiwanensis), Virus Genes 51 (2015) 148-151.

[8] L. Li, F. Giannitti, J. Low, C. Keyes, L.S. Ullmann, X. Deng, et al., Exploring the virome of diseased horses, J. Gen. Virol. 96 (2015) 2721-2733.

[9] K. Rosario, M. Marinov, D. Stainton, S. Kraberger, E.J. Wiltshire, D.A. Collings, et al., Dragonfly cyclovirus: a novel single-stranded DNA virus discovered in dragonflies (Odonata: Anisoptera), J. Gen. Virol. 92 (2011) 1302-1308.

[10] A. Dayaram, K.A. Potter, A.B. Moline, D.D. Rosenstein, M. Marinov, J.E. Thomas et al., High global diversity of cycloviruses amongst dragonflies, J. Gen. Virol. 94 (2013) 1827-1840.

[11] M. Padilla-Rodriguez, K. Rosario, M. Breitbart, Novel cyclovirus discovered in the Florida woods cockroach Eurycotis floridiana (Walker), Arch. Virol. 158 (2013) 1389-1392.

[12] K. Rosario, A. Dayaram, M. Marinov, J. Ware, S. Kraberger, D. Stainton, et al., Diverse circular ssDNA viruses discovered in dragonflies (Odonata: Epiprocta), J. Gen. Virol. 93 (2012) 2668-2681.
[13] L. Li, J.G. Victoria, C. Wang, M. Jones, G.M. Fellers, T.H. Kunz, et al., Bat guano virome: predominance of dietary viruses from insects and plants plus novel mammalian viruses, J. Virol. 84 (2010) 6955-6965.

[14] X. Ge, J. Li, C. Peng, L. Wu, X. Yang, Y. Wu, et al., Genetic diversity of novel circular ssDNA viruses in bats in China, J. Gen. Virol. 92 (2011) 2646-2653.

[15] F.E. Lima, S.P. Cibulski, H.F. Dos Santos, T.F. Teixeira, A.P. Varela, P.M. Roeche, et al., Genomic characterization of novel circular ssDNA viruses from insectivorous bats in Southern Brazil, PLoS One 10 (2015) e0118070.

[16] L. Li, T. Shan, O.B. Soji, M.M. Alam, T.H. Kunz, S.Z. Zaidi, et al., Possible cross-species transmission of circoviruses and cycloviruses among farm animals, J. Gen. Virol. 92 (2011) 768-772.

[17] M.F. Male, S. Kraberger, D. Stainton, V. Kami, A. Varsani, Cycloviruses: gemycircularviruses and other novel replication-associated protein encoding circular viruses in Pacific flying fox (Pteropus tonganus) faeces, Infect. Genet. Evol. 39 (2016) 279-292.

[18] Z. Wu, L. Yang, X. Ren, G. He, J. Zhang, J. Yang, et al., Deciphering the bat virome catalog to better understand the ecological diversity of bat viruses and the bat origin of emerging infectious diseases, ISME J. 10 (2016) 609-620.

[19] T.G. Phan, D. Mori, X. Deng, S. Rajindrajith, U. Ranawaka, Ng Fan, et al., Small circular single stranded DNA viral genomes in unexplained cases of human encephalitis, diarrhea, and in untreated sewage, Virology 482 (2015) 98-104.

[20] S.L. Smits, E.E. Zijlstra, J.J. van Hellemond, C.M. Schapendonk, R. Bodewes, A.C. Schurch, et al., Novel cyclovirus in human cerebrospinal fluid Malawi, 2010-2011, Emerg. Infect. Dis. 19 (2013) 1511-1513.

[21] Le V. Tan, M.D. de Jong, V.K. Nguyen, V.T. Nguyen, W. Taylor, H.F. Wertheim, et al., Limited geographic distribution of the novel cyclovirus CyCV- VN, Sci. Rep. 4 (2014) 3967.

[22] T.G. Phan, V. Luchsinger, L.F. Avendano, X. Deng, E. Delwart, Cyclovirus in nasopharyngeal aspirates of Chilean children with respiratory infections, J. Gen. Virol. 95 (2014) 922-927.

[23] S. Smits, C. Schapendonk, J. van Beek, H. Vennema, A. Schürch, D. Schipper, New viruses in idiopathic human diarrhea cases The Netherlands, Emerg. Infect. Dis. 20 (2014) 1218-1222.

[24] R. Johne, H. Muller, A. Rector, M. van Ranst, H. Stevens, Rolling-circle amplification of viral DNA genomes using phi29 polymerase, Trends Microbiol. 17 (2009) 205-211.

[25] L. Macera, M. Cortey, F. Maggi, J. Segales, T. Kekarainen, A novel rolling circle amplification assay to detect members of the family Anelloviridae in pigs and humans, Virus Res. 160 (2011) 424-427.

[26] M.C. Chan, S.W. Kwok, P.K. Chan, False- positive PCR detection of cyclovirus Malawi strain VS5700009 in human cerebrospinal fluid, J. Clin. Virol. 68 (2015) 76-78.

[27] F. Maggi, M. Bendinelli, Immunobiology of the torque teno viruses and other anelloviruses, Curr. Top. Microbiol. Immunol. 331 (2009) 65-90. 